Article

\title{
Delayed LY333013 (Oral) and LY315920 (Intravenous) Reverse Severe Neurotoxicity and Rescue Juvenile Pigs from Lethal Doses of Micrurus fulvius (Eastern Coral Snake) Venom
}

\author{
Matthew R. Lewin ${ }^{1,2, *}$, Lyndi L. Gilliam ${ }^{3}$, John Gilliam ${ }^{3}$, Stephen P. Samuel ${ }^{2,4}$, \\ Tommaso C. Bulfone ${ }^{1,2}$ (D) Philip E. Bickler ${ }^{5}$ and José María Gutiérrez ${ }^{6}$ (D) \\ 1 Ophirex, Inc., Corte Madera, CA 94925, USA; tommaso.bulfone@gmail.com \\ 2 California Academy of Sciences, San Francisco, CA 94118, USA; paulshania@yahoo.co.uk \\ 3 Department of Veterinary Clinical Sciences, Center for Veterinary Health Sciences, Oklahoma State \\ University, Stillwater, OK 74078, USA; l.gilliam@okstate.edu (L.L.G.); john.gilliam@okstate.edu (J.G.) \\ 4 Queen Elizabeth Hospital, Kings Lynn, Norfolk PE30 4ET, UK \\ 5 Anesthesia and Perioperative Care, University of California, San Francisco, CA 94143, USA; \\ bicklerp@anesthesia.ucsf.edu \\ 6 Instituto Clodomiro Picado, Facultad de Microbiología, Universidad de Costa Rica, San José 11501-2060, \\ Costa Rica; jose.gutierrez@ucr.ac.cr \\ * Correspondence: matt@ophirex.com
}

Received: 1 November 2018; Accepted: 14 November 2018; Published: 17 November 2018

\begin{abstract}
There is a clear, unmet need for effective, lightweight, shelf-stable and economical snakebite envenoming therapies that can be given rapidly after the time of a snake's bite and as adjuncts to antivenom therapies in the hospital setting. The sPLA2 inhibitor, LY315920, and its orally bioavailable prodrug, LY333013, demonstrate surprising efficacy and have the characteristics of an antidote with potential for both field and hospital use. The efficacy of the active pharmaceutical ingredient (LY315920) and its prodrug (LY333013) to treat experimental, lethal envenoming by Micrurus fulvius (Eastern coral snake) venom was tested using a porcine model. Inhibitors were administered by either intravenous or oral routes at different time intervals after venom injection. In some experiments, antivenom was also administered alone or in conjunction with LY333013. 14 of 14 animals (100\%) receiving either LY315920 (intravenous) and/or LY333013 (oral) survived to the $120 \mathrm{~h}$ endpoint despite, in some protocols, the presence of severe neurotoxic signs. The study drugs demonstrated the ability to treat, rescue, and re-rescue animals with advanced manifestations of envenoming. Low molecular mass sPLA2 inhibitors were highly effective in preventing lethality following experimental envenoming by $M$. fulvius. These findings suggest the plausibility of a new therapeutic approach to snakebite envenoming, in this example, for the treatment of a coral snake species for which there are limitations in the availability of effective antivenom.
\end{abstract}

Keywords: snakebite; envenoming; antidote; inhibitor; coral snake; Micrurus fulvius; PLA2; phospholipase A2; neurotoxicity; antivenom

Key Contribution: The small molecules LY315920 and LY333013, given intravenously and/or orally in a pig model of severe envenoming by M. fulvius, were effective with and without antivenom even at advanced stages of neurotoxicity. 


\section{Introduction}

Snakebite envenoming is a significant global health concern and has been recently included in the World Health Organization (WHO) list of Neglected Tropical Diseases [1]. Over 5 million people are affected every year by snakebites, and over $75 \%$ of the estimated 138,000 deaths occur outside of the hospital setting, where antivenom cannot be administered [2-4]. In total, there are an estimated 5.8 billion people worldwide living within the geographic range of venomous snakes. A disproportionate number of impoverished populations reside in hot-spots where there is a high risk of receiving a snakebite and are remote from hospital resources and antivenom [3]. Worldwide, snakebite envenoming is an occupational risk to the majority of people working in manually dominated agricultural settings [5,6]. There is a clear, unmet need for effective, heat stable, and economical broad-spectrum snakebite envenoming therapies based on drugs with a high volume of distribution that can be given rapidly and at the time of bite as well as an adjunct therapy to improve the efficacy of antivenoms [7,8].

All snake venoms contain multiple enzymatic and non-enzymatic components, including abundant phospholipases $\mathrm{A}_{2}$ (PLA2), which are major contributors to venom toxicity of the majority of the world's venomous snakes $[9,10]$. Snake venom secretory sPLA2 and sPLA2-like proteins play a fundamental role in neuromuscular paralysis, coagulopathy, cardiotoxicity, renal toxicity, and skeletal muscle necrosis that can result in rapid death or permanent disability [11-13]. Furthermore, there is an increasing body of evidence that mammalian homologs of venom sPLA2 also play a major contributory role in the endogenous inflammatory response, which might be involved in the response to snake venoms, including hemolysis, platelet dysfunction, and possibly fibrinogen depletion [14-18]. It is possible that the combined effects of venom and endogenous PLA2s has a critical role in the toxic inflammatory response, morbidity, and mortality resulting from snakebite envenoming.

Because of the central role played by snake venom sPLA2s, they are a logical target for therapeutics with active and peripheral site targets not accessible to antivenom therapies, owing to pharmacokinetic considerations and to the generally low antigenicity of PLA2s [19,20]. As a class of therapeutics, some limitations inherent to antivenoms (e.g., poor tissue penetration with a dependence on contact with circulating venom) are compounded by their perishable nature and the development of adverse reactions in a percentage of patients; thus, antivenoms have to be administered in health facilities by medical personnel [21].

By focusing on the enzymatic activity of sPLA2s, rather than their antigenicity, we have identified what could be a safe, potent set of compounds that can be readily re-purposed to timely address the cardinal life-threatening complications of snakebite envenoming in the field. LY315920 was first developed as a potent inhibitor of human sPLA2 for indications such as pancreatitis, sepsis, and cardiovascular disease [22]. Surprisingly, LY315920 and closely related compounds such as the orally-available pro-drug LY333013, are extremely potent inhibitors of 28 medically important venom sPLA2s from snake species of six continents [7]. These results have been replicated with several venoms both in vitro and in vivo in mice $[7,23,24]$. Both lead compounds have been through extensive human and animal testing, and although they have excellent safety profiles for short-term use, have never gained FDA approval and are now off patent [22,25]. Recently, we demonstrated that LY333013 given orally could rescue mice with treatment delays at time points past which specific Taipan (Oxyuranus scutellatus) antivenoms are effective [26]. LY315920 and its pro-drug LY333013, fit the profile of a low-cost, heat stable, easy to administer field antidote for snakebite envenoming, particularly for venoms whose main toxic actions are induced by PLA2s.

Herein, we show results from in vivo rescue studies with LY315920 and its pro-drug LY333013 in juvenile porcine models from lethal envenoming of $M$. fulvius venom. In animals, $M$. fulvius venom is known to cause neuromuscular paralysis, intravascular hemolysis, and myonecrosis [27-29]. M. fulvius venom was chosen for porcine testing because of its clinical relevance in North America, the fact that there is a scarcity of available antivenoms, and because its main toxic activities depend on the action 
of PLA2s [27]. In addition, M. fulvius venom proved to have high reliability in preliminary porcine lethality tests, reducing the likelihood of unnecessary animal use [30-33].

\section{Results}

Subcutaneous administration of $0.5-4.0 \mathrm{mg} / \mathrm{kg}$ M. fulvius venom killed all pigs within $6.5 \mathrm{~h}$, as shown in Figure 1. Given the similarity of the effects of these doses on survival, doses of $1 \mathrm{mg} / \mathrm{kg}$ and $0.5 \mathrm{mg} / \mathrm{kg}$ were ultimately used but only one of these doses was used in any experiment and in appropriate control/treatment pairs. The venom doses used correspond to the maximum plausible quantity of venom that could be delivered by the bite of a large Eastern coral snake [34]. The group receiving a $0.5 \mathrm{mg} / \mathrm{kg}$ venom dose had a mean survival time of $4 \mathrm{~h} 48 \mathrm{~min}$ (S.D. $=20.53 \mathrm{~min}$ ). All animals treated with LY315920 and/or LY333013 survived regardless of protocol $(\mathrm{N}=14)$. In two animals, attempts were made to assess whether the neurotoxic effect was due to alpha-neurotoxins acting at the cholinergic receptor of the motor end-plate of muscle fibers; a combination of edrophonium $(1 \mathrm{mg} / \mathrm{kg})$ and atropine $(0.02 \mathrm{mg} / \mathrm{kg})$ combined in the same syringe was administered slowly intravenously over one minute in two animals receiving a lethal dose of the venom. No clinically observable improvement in strength occurred, suggesting, but not proving, the absence of any contribution by post-synaptically acting alpha-neurotoxins [35,36]. Notably, no animal in the study required any additional analgesia more than the mandatory two initial doses required by protocol (see Materials and Methods Detail, Section 5).

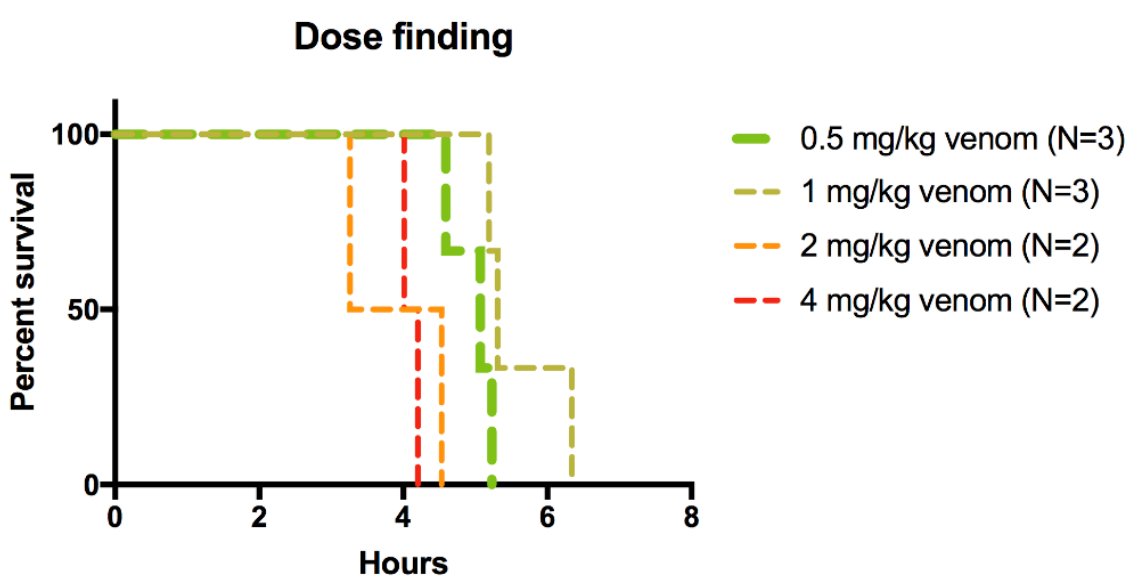

Figure 1. Kaplan Meier curves of lethality in pigs receiving various doses of M. fulvius venom.

\subsection{Rescue Experiments}

The first rescue study (Protocol A) produced 100\% lethality in the control group within $5 \mathrm{~h}$ and $32 \mathrm{~min}(n=2,1 \mathrm{mg} / \mathrm{kg}$ venom and excipient) while all of the animals in the treatment group survived for the length of the study ( $n=4,1 \mathrm{mg} / \mathrm{kg}$ venom, $5 \mathrm{mg} / \mathrm{kg}$ bolus of LY315920 with $2.5 \mathrm{mg} / \mathrm{kg}$ bolus every $6 \mathrm{~h}$ and $1 \mathrm{mg} / \mathrm{kg}$ as needed after $24 \mathrm{~h}$ ). Three out of four treatment pigs required only one $1 \mathrm{mg} / \mathrm{kg}$ LY315920 dose after the first $24 \mathrm{~h}$, and only one pig required two doses, see Figure 2A.

In protocol " $\mathrm{B}$ ", combinations of intravenous (IV) continuous infusion and an oral drug were tested. All groups were injected with $0.5 \mathrm{mg} / \mathrm{kg}$ of venom, followed by various rescue protocols. The control group reached mortality within $5 \mathrm{~h}$ and $6 \mathrm{~min}(n=2)$. All pigs in protocols B1, B2, and B3 survived to the end of the study period of $120 \mathrm{~h}$, as shown in Figure 2B.

When the oral drug, LY333013, was compared to antivenom (protocol C), the control group reached mortality within $5 \mathrm{~h}$ and $20 \mathrm{~min}(n=3)$. Again, all pigs submitted to the rescue protocol $\mathrm{C}$ survived the $120 \mathrm{~h}$ observation period, as shown in Figure 2C. Animals that where given antivenom within the first minutes of envenoming recovered, whereas those receiving antivenom after a $45 \mathrm{~min}$ delay suffered a delayed onset of clinical signs of severe envenoming. This delay caused the antivenom administration to fail when administered outside the time window during which it could be effective 
in neutralizing circulating venom. However, the pigs receiving a delayed administration of antivenom required fewer drug doses to reach the study endpoint, suggesting that the combination of drug and antivenom could have utility as a definitive treatment for snakebite even with significant delays in antivenom administration.

A) IV rescue

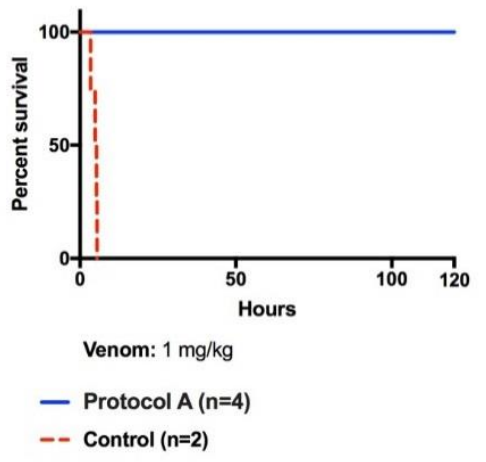

B) IV to Oral transition

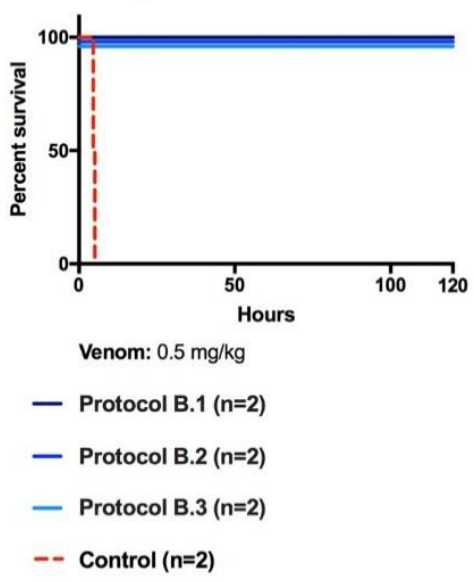

C) Oral only and antivenom rescue

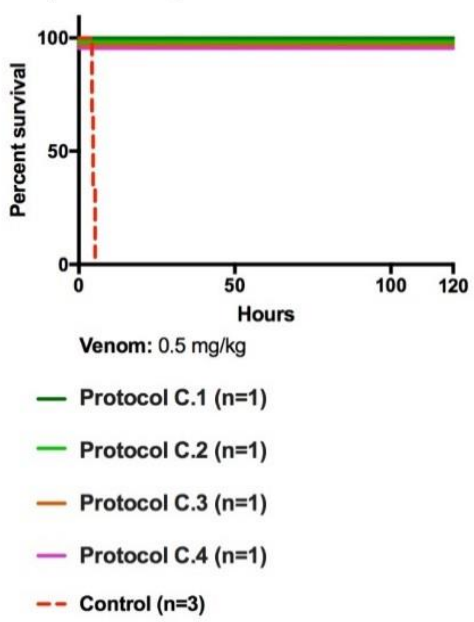

Figure 2. LY315920 (Intravenous) and LY3333013 (Oral) alone or in combination completely abrogated lethality induced by M. fulvius venom in different protocols: IV Rescue (A), IV to Oral transition (B) and Oral only and antivenom rescue (C) (see description of the various treatment protocols in the Materials and Methods section).

\subsection{Recovery from Coagulopathy}

Thromboelastography (TEG) and Sonoclot outputs in basal samples, i.e., before the onset of envenoming, showed normal coagulation, as shown in Figure 3. Animals injected with venom developed a profound coagulopathy at $30 \mathrm{~min}$, see Figure 3, as demonstrated by abnormal viscoelastic behavior. Treatment with oral LY333013 reverted coagulopathy in pigs, with partial correction by $60 \mathrm{~min}$ and complete recovery at $4 \mathrm{~h}$. Likewise, control groups receiving venom only developed alterations in the Activated Clotting Time and Prothrombin Time, whereas envenomed pigs receiving the drug showed corrections in the values of these tests, approaching those of basal determinations, see Figure 4. M. fulvius venom did not affect the platelet numbers but did alter the platelet function, as shown in Figure 4. This alteration was corrected in the various protocols in which the drug was administered after envenoming, see Figure 4.

Laboratory samples at baseline and during the course of study were taken to assess the effect of the drugs in myotoxicity and renal parameters. As shown in Figure 4, envenoming resulted in a drastic increment in plasma creatine kinase (CK) levels, underscoring the development of myonecrosis. Envenomed animals treated with the drug under various protocols had much smaller increments in plasma CK activity, evidencing the inhibition of myotoxicity. No significant changes in plasma creatinine levels were observed in envenomed pigs, compared to basal values, thus indicating the lack of nephrotoxic action in this particular model of envenoming, see Figure 4. On the other hand, envenomed animals developed intravascular hemolysis, as evidenced by the presence of reddish pigmented plasma one hour after envenoming, see Figure 3C. This effect was abolished in the groups treated with the inhibitor (not shown). Myotoxicity and intravascular hemolysis in envenomings by M. fulvius in animal models are due to the action of venom PLA2s [37], which explains the beneficial effect of the drug. 


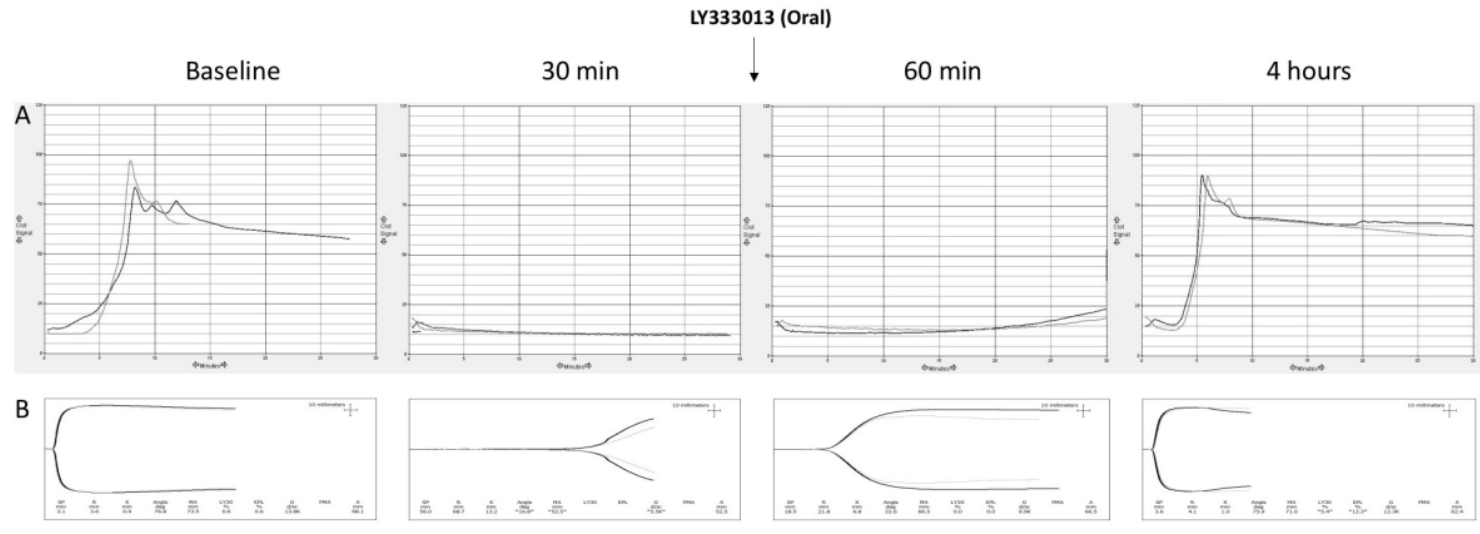

$\mathrm{C}$

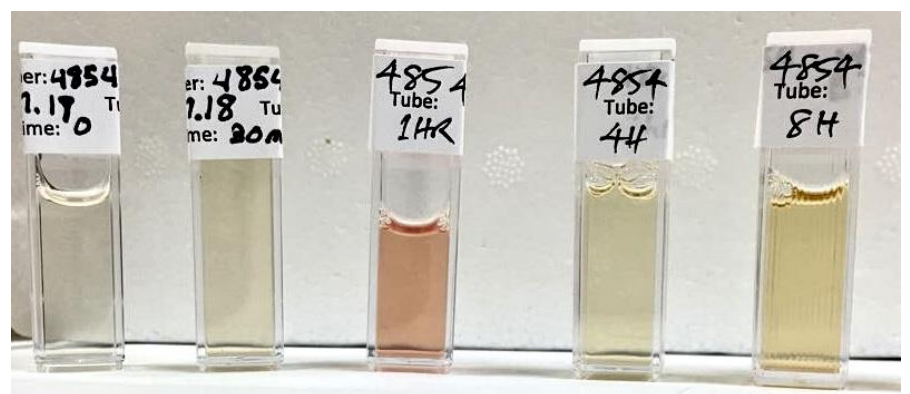

Figure 3. Evidence of systemic envenoming prior to initiation of treatment is illustrated by the incoagulability of blood. In this example, coagulopathy was corrected within a short time after oral administration of LY333013. Sonoclot (A) and Thromboelastography (TEG) (B). (C): A typical presentation of venom-induced gross intravascular hemolysis was frequently observed during the experiments. Samples correspond to plasma from pigs injected with $0.5 \mathrm{mg} / \mathrm{kg}$ venom and collected at times $0 \mathrm{~min}(1), 30 \mathrm{~min}(2), 1 \mathrm{~h} \mathrm{(3),} 4 \mathrm{~h} \mathrm{(4)}$ and $8 \mathrm{~h}(5)$. Notice the evident hemolysis in the sample at $1 \mathrm{~h}$.
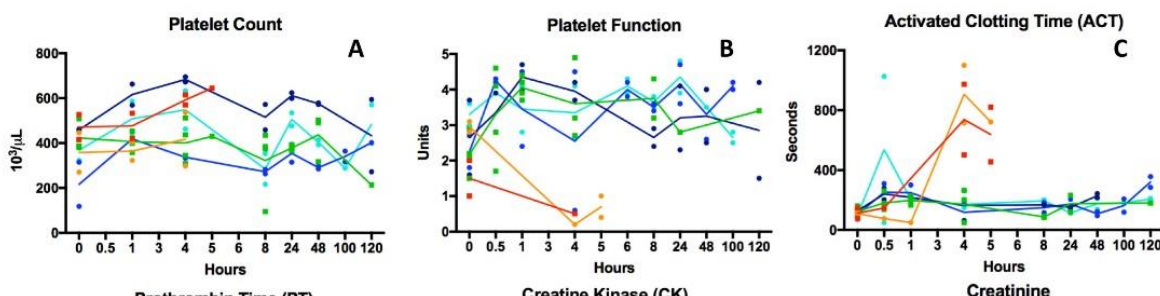

$\rightarrow$ Control $(0.5 \mathrm{mg} / \mathrm{kg}$ venom

- Control ( $1 \mathrm{mg} / \mathrm{kg}$ venom)

- Protocol $\mathrm{A}(1 \mathrm{mg} / \mathrm{kg}$ venom $)$

$\rightarrow$ Protocol B.1 (0.5 mg/kg venom)

$\rightarrow$ Protocol B.2 (0.5 mg/kg venom)

$\rightarrow$ Protocol B.3 (0.5 mg/kg venom)
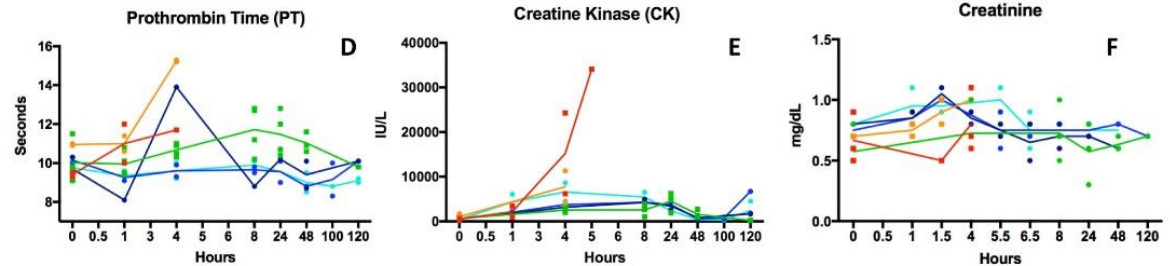

Figure 4. LY315920-treated animals showed a general preservation of hemostasis compared to controls. (A) Platelet counts remained normal but platelet function (B) was inhibited by venom. Platelet function was restored and maintained in the presence of drug. (C) Activated clotting time, (D) Prothrombin Time and (E) Creatine kinase largely remained within normal levels when animals were treated with SPLA2 inhibitors. Creatinine concentrations were normal for all subjects (F). Reference ranges: Platelet count 200-400 103/ $\mu$ L, Platelet Function 2-4.8 Units, ACT 69-221 s, PT 10.5-13.5 s, CK 100-400 IU/L, Creatinine $0.1-2 \mathrm{mg} / \mathrm{dL}$.

\subsection{Recovery from Neurotoxicity}

When the evolution of the clinical score was followed in envenomed pigs that did not receive any treatment, there was a rapid deterioration resulting in death within 5 and 6 h, see Figure 5 . 
The majority of pigs treated with the drugs did not develop any sign of clinical deterioration and survived during the study period, as shown in Figure 5. In contrast, one pig in each of the rescue protocols B1, C1, and C2 showed an initial deterioration of clinical status, which then recovered, whereas pig 1 in protocol C4 showed a notorious clinical deterioration which could not recover after delayed administration of antivenom. Its condition clearly improved, and the animal survived, after a delayed oral administration of the drug, as shown in Figure 5.
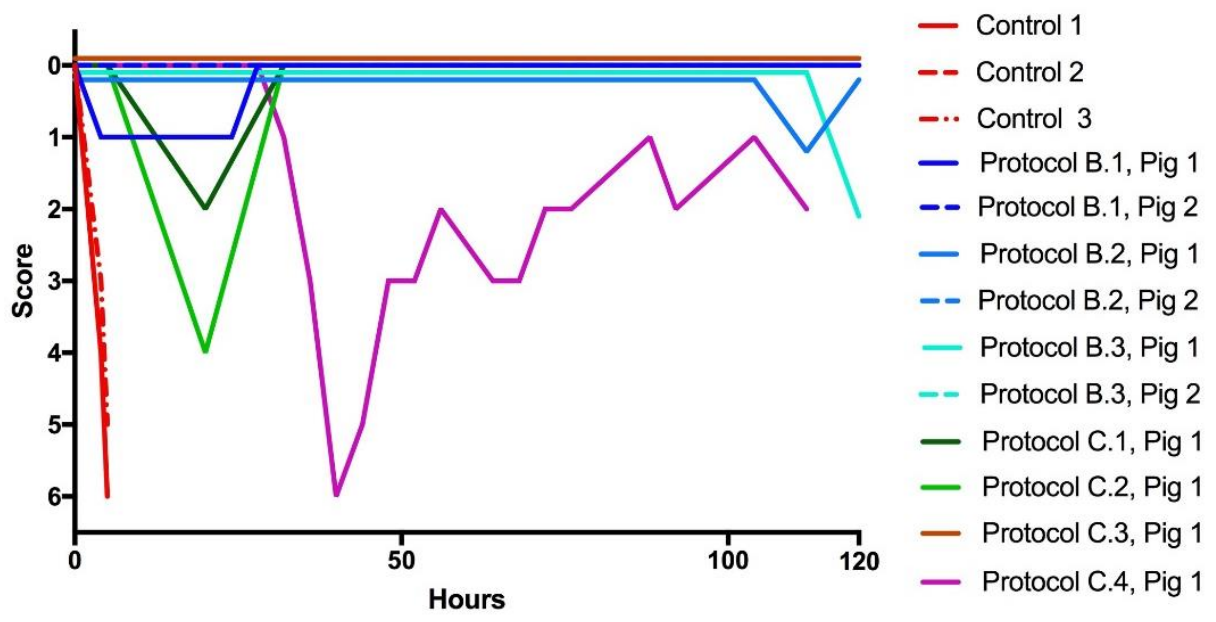

Figure 5. Clinical score in envenomed animals. All animals that received the test drug avoided or recovered from neurotoxicity. When rescue antivenom was not efficacious, the drug resolved severe neurotoxicity (Protocol C.4).

\subsection{Limitations}

In toto, all animals treated with oral or IV drug survived, but there are only a small number of animals for each group; therefore, a comprehensive understanding of each protocol's advantages or disadvantages is limited. Only three animals received antivenom (one each: immediately following envenoming and at $15 \mathrm{~min}$ and $45 \mathrm{~min}$ delays with decreasing efficacy over time). Future studies should be directed toward more a systematic dose finding for both antivenom and drug as they are likely to both be used in the clinical setting. For the purpose of this study, we stayed within LY333013 dose ranges and schedules previously tested in animals as well as Phase I and II human studies of these compounds that were previously evaluated for indications other than snakebite and never advanced to Food and Drug Administration (FDA) registration due to a lack of efficacy [22]. The results cannot yet be generalized to the neutralization of a broad range of snake venom sPLA2s and associated pathology but the toxin-specific approach is being increasingly investigated as a treatment for snakebite both alone and in conjunction with antivenom $[7,9,10,23,24,26]$. This was advantageous in guiding these experiments and to allow some reasonable comparison of results [30-33]. The domestic porcine model may be a stringent model to study gastrointestinal transit and absorption of drugs because gastric emptying in Sus domesticus is amongst the slowest of mammals and may have provided a more robust challenge to the oral drug, LY333013, than using minipigs bred for their accelerated gastrointestinal clearance [38]. All but one pig that was profoundly weak (Protocol C.4) were fed LY333013 in dog treats following recovery from anesthesia. Ensuring every bit of treat was consumed was difficult and if the treat became macerated it was challenging to get the pig to ingest every piece, thus some of the pigs may have received less than the full dose. One animal (Protocol B.3) required a new treat after refusing and spitting out the first offerings and likely received some additional drug for the first dose. In all animals where drug dosing was intermittent, neurological function showed waxing and waning consistent with the reported half-lives of the drugs. However, in all cases, where coagulopathy recurred or weakness reappeared, the drugs effectively reversed the clinical manifestations of envenoming within one to four hours. Animals cannot specifically express the subjective experience of pain, so the 
lameness score is a clinically used method used as a helpful guide for practitioners to quantify and communicate each case's clinical signs. Using the system also creates a benchmark for monitoring the improvement or worsening of the disease. No animal in the study ever presented with isolated weakness of a limb-weakness was generalized and flaccid, while nociceptive type responses were typically manifested as a limp or forelimb withdrawal. We did not use electrophysiological methods to ascertain twitch responses or definitively eliminate the possibility of alpha-neurotoxin effects. This is because different alpha-neurotoxins show different affinities towards nicotinic cholinergic receptors (nAChR) of different animals. It may simply be that the high affinity of the alpha toxins towards the nAChR cannot be overcome by anticholinesterases. One straightforward method of showing this in other models is the isolated chick-biventer nerve-muscle preparation, which differentiates pre-synaptic from post-synaptic neurotoxicity $[35,36]$. However, this was not part of the present study, which was conducted on pigs. While the non-reversal of paralysis by acetylcholinesterase inhibitors (AChEIs) in pigs does not conclusively say that the paralysis was due to pre-synaptic neurotoxins, virtually all neurological symptoms (and coagulopathy) were rapidly abolished by the administration of sPLA2 inhibitors, but not AChEIs, suggesting sPLA2 toxicity was the main cause of weakness.

Finally, we used high doses of venom. It is possible that, using lower doses of venom, pigs could have been cured by fewer or lower drug doses. Venom sequestered in the fatty subcutaneous tissues of the pig could possibly be leaching out for days and require additional treatment. We subjected the drugs to much more stringent testing conditions than those reported in the literature and for what is required by industry and the World Health Organization (WHO) in the testing of antivenoms (which involve premixing of venom with antivenom prior to challenging animals) [39]. Our model is arguably more robust and amenable to making direct comparisons of therapeutics with different modes of delivery and mechanism and may argue for higher standards in the field as a whole [39].

\section{Discussion}

Continuous infusions or repeated bolus doses of LY315920 and oral LY333013 resulted in 100\% survival following severe, experimental, M. fulvius envenoming in pigs. Rescue experiments with a single-dose of LY315920 produced a significant improvement in survival times compared to controls, but after $10+\mathrm{h}$ from the time of envenoming the symptoms often reappeared, probably due to a delayed venom absorption from a depot in the tissue site where venom was injected. In addition, this suggests that the half-life of the experimental drugs will make single dose therapy for severe envenoming unlikely to result in sustained clinical resolution. However, the ability to treat, rescue, and re-rescue animals at late stages of envenoming, including those already exhibiting severe neurological deficits and clotting disturbances, suggests these drugs might have unexpected versatility in a variety of clinical settings for both human and veterinary applications in M. fulvius envenoming.

We found that drug rescue where antivenom was initially unsuccessful resulted in a lowered drug requirement-i.e., fewer pro re nata (PRN) doses to maintain normal neurological function to the end of the study. This suggests that the circulating antivenom was able to capture drug-neutralized venom diffusing back into circulation from the peripheral tissues. However, confirmation of this requires more detailed studies.

PLA2s are predominant in M. fulvius venom and are largely responsible for its neurotoxicity [27]. Hence, in the dichotomic pattern described for Micrurus venoms from the proteomic standpoint, i.e., PLA2-rich and alpha-neurotoxin-rich venoms [40], M. fulvius fits within the first group. In addition, besides neurotoxicity (the primary toxicity in humans) other toxic activities associated with this venom are witnessed in different animal species (e.g., myotoxicity and intravascular hemolysis) and are also caused by the action of PLA2s [37]. This largely explains the success of these potent PLA2 inhibitors in abrogating lethality, myonecrosis, and hemolysis in our experiments in pigs. Moreover, PLA2s are known to affect coagulation and platelet function $[13,41]$, hence explaining the ability of the inhibitors to abrogate these toxic effects as well. Our observations with edrophonium and atropine suggest that post-synaptically acting alpha-neurotoxins are not likely to play a significant role in this 
venom's neurotoxicity, therefore supporting the concept that pre-synaptically acting PLA2s are the main neurotoxic components in M. fulvius venom. The key role played by PLA2s in the overall toxicity of $M$. fulvius venom makes it highly amenable to treatment with the PLA2 inhibitors tested in this study, a finding of potential impact in light of the current scarcity of coral snake antivenoms in the US.

Snakebite is an ancient scourge recognized in mythology and history since Biblical times but only recently as a neglected tropical disease by the WHO [1,42]. Our findings could represent a first crucial step away from the complete dependence on antivenom in combating the deadly effects of snakebite-especially, with the potential for developing an oral antidote to be taken at the time of a snake's bite. Use of heat-stable, orally bioavailable, economical small molecules for initial and adjunct treatment for snakebite has the potential to substantially reduce mortality caused by snakebite in rural areas of the developing world. Additionally, this treatment could also reduce the mortality and morbidity associated with settings in which snakebite is an occupational hazard [5,6]. Further research is warranted on developing inhibitors to other enzymatic components of snake venom, such as metalloproteases [43]. Repositioning, the strategy utilized to repurpose LY315920 and LY333013 from their initial intended uses, offers the potential for low costs of development for future inhibitors. Combinations of multiple inhibitors and other antibodies could provide quite effective, safe, and affordable treatment for snakebite envenoming.

The inhibition of enzymatic activity of sPLA2s and other venom components by small molecule inhibitors of specific toxins could address many, but not all, limitations of antivenom. Notably, small molecule antidotes could potentially reduce the volume of antivenom administered, thus increasing the efficacy of antivenoms having a low potency against some venoms $[8,21,43,44]$ while reducing the cost to the patient and to the healthcare system [45]. Recent US coral snake guidelines recommend availability of an antidote within one hour-the results of this paper suggest that LY315920 and LY333013 could fulfill these criteria. For example, neurologically intact patients could take the oral antidote while compromised patients could initially be treated with an IV formulation and transition to an oral therapy on recovery. In the US, there is currently no production or availability of previously approved coral snake antivenoms and these bites, while unusual, can be life-threatening, especially to children [46-49]. The 3-substituted indoles, such as LY315920 and/or LY333013, could offer a plausible, definitive treatment program for M. fulvius envenomed patients.

In conclusion, our findings suggest that LY315920 and/or LY333013 are likely to be effective in abrogating the main clinical manifestations in envenoming by M. fulvius and could apply to other types of envenoming as well $[7,23,24,26]$. Moreover, they support the concept that these drugs may potentiate the therapeutic action of coral snake antivenoms and others [26]. Owing to the current scarcity of Micrurus antivenoms in the US, the possibility of using these drugs in the management of these envenomings should lead to the design of clinical trials to assess their efficacy.

\section{Materials and Methods}

\subsection{Venom}

The venom of M. fulvius was purchased from Medtoxin Venom Laboratories (Deland, FL, United States of America (Lot 010918). Venom stock solutions $(10 \mathrm{mg} / \mathrm{mL}$ ) were prepared fresh daily in saline solution, and dilutions were performed in order to reach the desired venom dilutions to be injected.

\subsection{Antidotes, Excipients, and Antivenom}

LY315920 HCl (CAS 172732-42-5; ChemieTek, Indianapolis, Indiana) or LY333013 (CAS 172733-08-3; provided by Ophirex, Inc., Corte Madera, CA, USA) emulsions mixed into Greenies Hickory Smoke Flavored Pill Pockets (Mars Petcare, McLean, VA, USA) were prepared daily for each study. Control animals received excipients administered in exactly the same manner as the IV drugs. Boluses of LY315920 were administered manually over $15 \mathrm{~min}$ with continuous rate infusions (Vet/IV 2.2 Infusion Pump (Heska), Lubland, CO, USA) at a drug dosage of $0.67 \mathrm{mg} / \mathrm{kg} / \mathrm{hour}$ 
according to the methods for previous Phase II human clinical trials for sepsis [50]. In the case of orally administered LY33301, the dose was $10 \mathrm{mg} / \mathrm{kg}$ (as was the dose administered to subjects in some human clinical safety trials) by offering the treats following emergence from anesthesia or by nasogastric feeding tube as an emulsion when animals were too weak to swallow. Antivenom: The monospecific Coral-ICP Antivenom produced at Instituto Clodomiro Picado (University of Costa Rica; batch number 5610615ACL) was used. It is a whole IgG preparation obtained by caprylic acid precipitation [51] from the plasma of horses immunized with the venom of Micrurus nigrocinctus. This antivenom is effective in the neutralization of M. fulvius venom [52].

\subsection{Animals}

A total of twenty-four mixed breed female juvenile Sus domesticus purchased through a USDA-pproved dealer were utilized in this study. The animals were anesthetized, catheterized, and euthanized according to methodology detailed in Materials and Methods Detail (Section 5).

\subsection{Ethical Approval}

The study and protocols were approved by the Institutional Animal Care and Use Committee at Oklahoma State University and per requirements of U.S. Federal Contract: W81XWH-17-C-0069, Ethical approval code: VM-17-31 Date of approval: 28 November 2017.

\subsection{Study Period}

The study period was $120 \mathrm{~h}$ from the time of experimental envenoming. Additional information regarding monitoring and euthanasia is included in Materials and Methods Detail (Section 5).

\subsection{Envenoming and Rescue Experiment Protocols}

Various doses of venom $(0.5 \mathrm{mg} / \mathrm{kg}, 1.0 \mathrm{mg} / \mathrm{kg}, 2.0 \mathrm{mg} / \mathrm{kg}$, and $4.0 \mathrm{mg} / \mathrm{kg})$ were injected using a 26 gauge 0.5 inch needle in the distal lateral portion of the right antebrachium of the subject animals, see Tables 1 and 2. The needle was inserted approximately $3 \mathrm{~mm}$ below the skin into the subcutaneous tissues and venom was injected. The time-course of deaths was followed in order to select a dose of venom for the remainder of the study. The same veterinarian (LLG) administered every dose of venom throughout the entire study period. Rescue experiments with study drugs or antivenom were carried out and several rescue protocols, as described in Table 2, were used after envenoming. Briefly, the ability of the sPLA2 inhibitors alone and in combination with antivenom were assessed in proof-of-concept efficacy experiments and in scenarios designed to potentially model clinical use alone or in combination with antivenom. IV drugs were administered either as boluses or by continuous rate infusion (CRI).

Table 1. Lethality study in juvenile pigs injected with Eastern coral snake (M. fulvius) venom by the subcutaneous route (SC).

\begin{tabular}{ccc}
\hline Group & Number Animals Per Group & Venom Dose (mg/kg) \\
\hline 1 & 2 & $4 \mathrm{mg} / \mathrm{kg}$ \\
2 & 2 & $2 \mathrm{mg} / \mathrm{kg}$ \\
3 & 3 & $1 \mathrm{mg} / \mathrm{kg}$ \\
4 & 3 & $0.5 \mathrm{mg} / \mathrm{kg}$ \\
\hline
\end{tabular}


Table 2. Rescue study using LY315920 and LY333103 to treat juvenile pigs injected with Eastern coral snake venom (route: SC).

\begin{tabular}{|c|c|c|c|c|}
\hline Protocol & $\begin{array}{c}\text { Number Animals } \\
\text { Per Group }\end{array}$ & Treatment & Venom Dose Level & Drug (and/or Antivenom) Dose \\
\hline Protocol A & 4 & $\begin{array}{c}\text { Venom } \\
+ \\
\text { LY315920 (i.v.) }\end{array}$ & $1 \mathrm{mg} / \mathrm{kg}$ & $\begin{array}{l}\text {-Loading dose: } 5 \mathrm{mg} / \mathrm{kg} \text { i.v. over } 15 \mathrm{~min} \text {. } \\
-2.5 \mathrm{mg} / \mathrm{kg} \text { i.v. bolus } \mathrm{q} 6 \mathrm{~h} \times 24 \mathrm{~h} \\
-1 \mathrm{mg} / \mathrm{kg} \text { i.v. prn weakness / coagulopathy }\end{array}$ \\
\hline Protocol B.1 & 2 & $\begin{array}{c}\text { Venom } \\
+ \\
\text { LY315920 (i.v.) then } \\
\text { LY333013 (p.o) }\end{array}$ & $0.5 \mathrm{mg} / \mathrm{kg}$ & $\begin{array}{l}\text {-Loading dose: } 1 \mathrm{mg} / \mathrm{kg} \text { i.v. immediately } \\
\text {-CRI i.v. } 0.67 \mathrm{mg} / \mathrm{kg} / \mathrm{h} \times 24 \mathrm{~h} \\
\text {-Oral } 200 \mathrm{mg} \mathrm{q} 6 \mathrm{~h} \times 4 \text { then } 100 \mathrm{mg} \text { PO q6 h prn } \\
\text { weakness / coagulopathy }\end{array}$ \\
\hline Protocol B.2 & 2 & $\begin{array}{c}\text { Venom } \\
+ \\
\text { LY315920 (i.v.) then } \\
\text { LY333013 (p.o) }\end{array}$ & $0.5 \mathrm{mg} / \mathrm{kg}$ & $\begin{array}{l}\text {-Loading dose: } 1 \mathrm{mg} / \mathrm{kg} \text { i.v. ( } 15 \mathrm{~min} \\
\text { after envenoming) } \\
\text {-CRI i.v. } 0.67 \mathrm{mg} / \mathrm{kg} / \mathrm{h} \times 24 \mathrm{~h} \\
\text {-Oral loading dose of } 400 \mathrm{mg} \text { PO } 4 \mathrm{~h} \text { prior to ending } \\
\text { the CRI followed by } 200 \mathrm{mg} \text { q } 6 \mathrm{~h} \text { for } 12 \mathrm{~h} \text { then } 100 \\
\mathrm{mg} \text { PO q } 6 \mathrm{~h} \text { prn weakness / coagulopathy }\end{array}$ \\
\hline Protocol B.3 & 2 & $\begin{array}{c}\text { Venom } \\
+ \\
\text { LY333013 (p.o) }\end{array}$ & $0.5 \mathrm{mg} / \mathrm{kg}$ & $\begin{array}{l}-400 \mathrm{mg} \text { PO loading dose (15 min delay) } \\
-200 \mathrm{mg} \text { PO q6 } \mathrm{h} \text { for } 12 \mathrm{~h} \\
-100 \mathrm{mg} \text { PO q6 } \mathrm{h} \text { for } 36 \mathrm{~h} \\
-100 \mathrm{mg} \text { PO q6 h prn weakness/coagulopathy }\end{array}$ \\
\hline Protocol C.1 & 1 & $\begin{array}{c}\text { Venom } \\
+ \\
\text { Antivenom }\end{array}$ & $0.5 \mathrm{mg} / \mathrm{kg}$ & $\begin{array}{l}-46.4 \mathrm{~mL} \text { antivenom i.v. }(1 \mathrm{~mL} \text { antivenom } / 0.125 \mathrm{mg} \\
\text { venom) (15 min post-venom) }\end{array}$ \\
\hline Protocol C.2 & 1 & $\begin{array}{c}\text { Venom } \\
+ \\
\text { Antivenom } \\
+ \\
\text { LY333013 (p.o) }\end{array}$ & $0.5 \mathrm{mg} / \mathrm{kg}$ & $\begin{array}{l}-67.2 \mathrm{~mL} \text { antivenom i.v. }(1 \mathrm{~mL} \text { antivenom/0.125 } \mathrm{mg} \\
\text { venom })(>45 \mathrm{~min} \text { post-venom }) \\
-67.2 \mathrm{~mL} \text { antivenom i.v. prn weakness/coagulopathy } \\
(1 \mathrm{~mL} \text { antivenom } / 0.125 \mathrm{mg} \text { venom }) \\
\text {-Rescue with LY333013 } 200 \mathrm{mg} \mathrm{PO} \times \mathrm{q} 6 \mathrm{~h} \text { prn } \\
\text { weakness/coagulopathy }\end{array}$ \\
\hline Protocol C.3 & 1 & $\begin{array}{c}\text { Venom } \\
+ \\
\text { LY333013 (p.o) }\end{array}$ & $0.5 \mathrm{mg} / \mathrm{kg}$ & $\begin{array}{l}-200 \mathrm{mg} \text { PO (>45 min post-venom) } \\
-200 \mathrm{mg} \text { PO q6 } 24 \mathrm{~h} \\
-100 \mathrm{mg} \text { PO q6 h for } 24 \mathrm{~h} \\
-200 \mathrm{mg} \text { PO weakness/coagulopathy }\end{array}$ \\
\hline Protocol C.4 & 1 & $\begin{array}{c}\text { Venom } \\
+ \\
\text { LY333013 (p.o) } \\
+ \\
\text { Antivenom }\end{array}$ & $0.5 \mathrm{mg} / \mathrm{kg}$ & $\begin{array}{l}-200 \mathrm{mg} \text { PO ( }>45 \mathrm{~min} \text { delay) } \\
-200 \mathrm{mg} \text { PO } \mathrm{q} 6 \mathrm{~h} \text { for } 12 \mathrm{~h} \\
\text { Drug withdrawn } \\
\text {-Rescue with antivenom i.v. ( } 1 \mathrm{~mL} / 0.125 \mathrm{mg} \text { of } \\
\text { venom) prn weakness / coagulopathy } \\
\text { If no response to antivenom: } \\
\text {-Rescue with } 200 \mathrm{mg} \text { PO q6 h prn } \\
\text { weakness/coagulopathy }\end{array}$ \\
\hline
\end{tabular}

\subsection{Clinical Assessment of the Severity of Envenoming}

The evolution of the severity of clinical manifestations in envenomed animals was followed by the criteria indicated in Table 3. On occasion, animals favored the leg (suggestive of pain or tenderness) into which venom was injected. This was separately assessed by the lameness score for the purpose of pain management (see Post-Envenoming Analgesia). 
Table 3. Clinical score used in the assessment of the severity of envenoming.

\begin{tabular}{cl}
\hline Score & \multicolumn{1}{c}{ Clinical Picture } \\
\hline 0 & $\begin{array}{l}\text { Normal activity, interested in food/water/toys, normal grunting, curious about } \\
\text { environment, responds normally to stimulation by moving away, rises easily and quickly } \\
\text { from recumbency when stimulated. }\end{array}$ \\
& $\begin{array}{l}\text { Normal movement around pen, reduced interest in food/water/toys, reduced interaction } \\
\text { with environment or caretakers, rises from recumbency and moves away when stimulated. }\end{array}$ \\
& $\begin{array}{l}\text { Evidence of weakness in one or more limbs, reduced interest in food/water/toys, reduced } \\
\text { responsiveness to stimulation but still able to rise normally from recumbency and remain } \\
\text { standing }>3 \text { min. }\end{array}$ \\
& $\begin{array}{l}\text { Significant evidence of weakness (dog-like sitting, treading in back legs after rising) but } \\
\text { able to rise unassisted when stimulated and stays standing }>15 \text { s but }<3 \text { min, some interest } \\
\text { in food/water/toys. } \\
\text { Significant evidence of weakness (dog-like sitting, sternal or lateral, treading in back legs } \\
\text { after rising), requires assistance to rise but can stand longer than } 10 \mathrm{~s} \text { on their own once } \\
\text { assisted to stand. } \\
\text { Significant evidence of weakness (dog-like sitting, sternal or lateral, treading in back legs } \\
\text { after rising), unable to rise without assistance, remains standing }<10 \text { s. } \\
\text { Marked evidence of weakness (sternal or lateral recumbency) unable to rise even with } \\
\text { assistance. Meets criteria for Euthanasia }\end{array}$ \\
5 &
\end{tabular}

\subsection{Laboratory Tests}

A venous blood sample was drawn through the catheter immediately following placement for baseline blood chemistry, complete blood count, coagulation panel tests (prothrombin time (PT), partial thromboplastin time, and dynamic viscoelastic coagulometry (TEG and Sonoclot ${ }^{\circledR}$ ). More information on laboratory tests are detailed in the Materials and Methods Detail (Below).

\section{Materials and Methods Detail}

Venom: The venom of M. fulvius was purchased from Medtoxin Venom Laboratories (Deland, FL, USA) (Lot 010918). Venom stock solutions $(10 \mathrm{mg} / \mathrm{mL})$ were prepared fresh daily in saline solution, and dilutions were performed in order to reach the desired venom dilutions to be injected.

Antidotes and Excipients: LY315920 HCl (CAS 172732-42-5; ChemieTek, Indianapolis, Indiana, $>99.9 \%$ purity by NMR, MS and HPLC) or an LY333013 (CAS 172733-08-3; provided by Ophirex, Inc. of Corte Madera, CA, USA) $>99.9 \%$ pure by NMR, MS and HPLC) emulsion mixed into Greenies Pill Pockets (Mars Petcare, McLean, VA, USA) were prepared daily for each study and each subsequent day of the study. Briefly, LY315920 was weighed as a powder and mixed $w / w$ in 1:1 sodium citrate and 1:2 mannitol followed by dissolution in $8.4 \%$ sodium bicarbonate to the final desired concentration of $5 \mathrm{mg} / \mathrm{mL}$ LY315920. Particulates were filtered using $0.22 \mu \mathrm{m}$ filters. Control animals received the intravenous (IV) sodium citrate/mannitol solutions without LY315290, and excipients were administered exactly as were the IV drugs. Boluses were administered manually over $15 \mathrm{~min}$ and continuous rate infusions (Vet/IV 2.2 Infusion Pump (Heska), Lubland, CO, USA) at $0.67 \mathrm{mg} / \mathrm{kg} / \mathrm{hour}$ according to the methods for previous Phase II human clinical trials for sepsis [50]. The oral drug (LY333013) was prepared as a slurry as previously described [26]. Briefly, the drug was mixed with $8 \% w / w$ gum Arabic and then mixed into Greenies Pill Pockets. In one instance, the study animal became too weak to swallow on its own and the drug was administered via the orogastic route in gum Arabic alone. Study drugs were prepared by the study sponsor for intravenous administration and by sponsor or Oklahoma State University (OSU) veterinarians for oral administration studies when the sponsor was not present.

Antivenom: The monospecific Coral-ICP Antivenom produced at Instituto Clodomiro Picado (University of Costa Rica; batch number 5610615ACL) was used. It is prepared from the plasma of horses immunized with the venom of the coral snake, M. nigrocinctus. It is made of whole IgG molecules purified by caprylic acid precipitation [51]. The Median Effective Dose $\left(\mathrm{ED}_{50}\right)$ of this 
antivenom against the venom of $M$. nigrocinctus is $0.4 \mathrm{mg}$ venom $/ \mathrm{mL}$ antivenom. This antivenom neutralizes the lethal and myotoxic activities of the venom of $M$. fulvius [52].

Animals Detail: Swine were housed in approved housing under a 12:12 light-dark cycle with ad libitum water and feed with the exception of an $8 \mathrm{~h}$ fast prior to anesthesia induction. All pigs were identified by ear tags. Pigs were acclimated to their new environment for 4-7 days prior to beginning the study. During this period, all animals were visually examined by trained laboratory personnel twice daily for any signs of illness. None of the pigs exhibited signs of illness prior to beginning the project. Pigs were weighed on the morning of the study and given a complete physical examination by Oklahoma State University animal husbandry staff (Control $12.72 \pm 2.48 \mathrm{~kg}$, treated $14.82 \pm 2.28 \mathrm{~kg}$ ( $p$-value: 0.18$)$ ). No animals were dropped from the study in either the control or experimental groups. All animals were fasted for a minimum of $8 \mathrm{~h}$ prior to anesthesia induction.

Housing: Swine were housed in pens (14 square feet) with raised plastic flooring to minimize contact with urine and feces. The pens allowed for individual or group housing depending on the phase of the study. During the acclimation period, pigs were group housed. Once intravenous catheters were placed, the pigs were individually housed to avoid the destruction of the catheters. Fresh water and feed were available at all times to the pigs during the studies with the exception of an 8-h fast prior to the day of catheter placement. Daily care of the pigs was provided by the centralized animal care unit, Animal Resources, as part of the Center for Veterinary Health Sciences' animal care program accredited by AAALAC International. Environment: Swine were housed in a temperature-controlled environment with a 12/12 light-dark cycle. Animals were identified by ear tags provided by the USDA.

Anesthesia, Instrumentation, and Monitoring: Pigs were anesthetized using the following protocol: midazolam $(5 \mathrm{mg} / \mathrm{mL})$ was administered intramuscularly using a 20-gauge, 1-inch needle in the semimembranosus/semitendinosus region at a dose of $0.25 \mathrm{mg} / \mathrm{kg}$. Pigs were allowed to rest quietly in their pen and become sedated for $15 \mathrm{~min}$. Pigs were then anesthetized utilizing inhalant isoflurane given via an anesthetic mask. Once pigs were anesthetized they were endotracheally intubated and placed on maintenance isoflurane gas. Pigs were instrumented with a temperature probe and continuous cardiac rhythm monitoring (ECG). Heart rate, respiratory rate, and temperature were monitored every $15 \mathrm{~min}$ to measure anesthetic depth. Once the pigs were at an acceptable depth of anesthesia, intravenous and intra-arterial catheters were placed according to the following protocols.

Intravenous catheter placement: With pigs in dorsal recumbency, the front legs were retracted caudally until they were close to parallel with and secured to the surgery table. A triangle was visualized utilizing the caudal ramus of the mandible, the lateral manubrium and medial portion of the point of the shoulder and was sterilely prepared. Initially, catheters were blindly placed utilizing these landmarks and based on the procedure described by Fluornoy and Mani [53]. However, ultrasound guidance proved to increase the efficiency and safety of the procedure and so was employed. Briefly, a $18-5 \mathrm{mHz}$ linear probe was placed inside a sterile glove to enable the use of ultrasound while maintaining sterility and the jugular vein was visualized. A $5 \mathrm{fr} 13 \mathrm{~cm}$ double lumen central line catheter made by Arrow was inserted using standard Seldinger technique with the guide needle for the over the wire catheter was placed under ultrasound guidance. The catheter was then placed according to standard procedure over the wire catheter placement technique. Catheters were secured in place using 0 PDS suture and the catheters were wrapped with 4-inch Elastikon bandages.

Intra-arterial catheter placement: Arterial catheters (20 g, $1.88 \mathrm{in})$ were placed in the femoral artery and secured using 0 PDS suture, super glue, and 2-inch Elastikon bandages. Invasive blood pressure was measured using the arterial catheter every 15 min during anesthesia.

Post-envenoming analgesia: Analgesia (Buprenorphine $0.05 \mathrm{mg} / \mathrm{kg} \mathrm{IM}$ ) was given to all pigs prior to venom administration, at $4 \mathrm{~h}$ post envenoming, and then as needed every $4 \mathrm{~h}$ for a behavior indicating pain as judged by the attending veterinarian (e.g., limping or guarding of envenomed forelimb independent of overall neurological examination-e.g., generalized weakness clinically indicative of systemic neurotoxicity). For notation purposes, the assessment of pain was modified from the Obel laminitis grading system and the AAEP Lameness Scale. 
Euthanasia: Pigs were euthanized or given rescue treatment if they reached a clinical score of 5 for two consecutive evaluations or if they reached a clinical score of 6 at any one evaluation. If they did not respond to rescue treatment they were humanely euthanized. All pigs were submitted for postmortem evaluation.

Study Period Detail: The pigs were monitored throughout the study period as follows:

Pigs were given a clinical score to record specific and general neurological status of the animals in a predetermined manner, see Table 3 of the manuscript and Figure 5 of results:

(1) Every $15 \mathrm{~min}$ post venom administration for the first $4 \mathrm{~h}$ following recovery from general anesthesia.

(2) From $4 \mathrm{~h}$ to $8 \mathrm{~h}$ post venom administration, pigs were given a clinical and lameness (veterinary surrogate for pain) score every $30 \mathrm{~min}$.

(3) From $8 \mathrm{~h}$ to $48 \mathrm{~h}$ post venom administration pigs were given a clinical and lameness score every hour.

(4) From $48 \mathrm{~h}$ to $96 \mathrm{~h}$ pigs were given a clinical and lameness score every $6 \mathrm{~h}$.

All monitoring was done in person until $48 \mathrm{~h}$. After $48 \mathrm{~h}$, if pigs were asymptomatic they were observed in person twice daily and monitored by video for the other time points. If pigs were noted to be showing signs of pain (lameness score of 3 or greater) or distress (down and unable to rise, dragging hind legs, visible signs of dyspnea such as open mouth breathing or abdominal press when breathing, or a clinical score of 4 or greater) one of the study veterinarians examined the pig in person within $1 \mathrm{~h}$ of noting abnormal signs. Pigs that experienced life-threatening toxicity defined as a clinical score of 5 for two consecutive observations or a clinical score of 6 once either received immediate treatment with the study drug or antivenom or were humanely euthanized using $39 \%$ sodium pentobarbital given intravenously.

In lethality-dose-finding studies, to deduce if the weakness was due to toxicity from alpha-neurotoxins which bind to the nicotinic cholinergic receptor at the motor end-plate, animals were challenged with edrophonium and atropine. Pigs were given a combination of edrophonium $(1 \mathrm{mg} / \mathrm{kg})$ and atropine $(0.02 \mathrm{mg} / \mathrm{kg})$ combined in the same syringe and given slowly intravenously over one minute and did not exhibit any changes in condition ( $n=2$ animals), thus indicating that neurotoxicity in this model is based on presynaptic activity of neurotoxins. This protocol was therefore discontinued.

Laboratory Test Details: An arterial blood sample was collected and assayed to measure $\mathrm{PaO} 2$ and $\mathrm{PaCO} 2$ during anesthesia at baseline and post venom just prior to recovery to ensure animals adequately oxygenated. There were no hypoxic episodes unrelated to envenoming and oxygenation/ventilation did not reverse venom-induced weakness (data not shown). Venous blood samples were drawn through the catheter immediately following placement for baseline blood chemistry, complete blood count, prothrombin time (PT), and dynamic viscoelastic coagulometry (TEG [54] and Sonoclot ${ }^{\circledR}$ ). All laboratory testing, with the exception of the Sonoclot and TEG, was performed by Antech Diagnostics (Stillwater, OK, USA). In addition, after centrifugation of blood, the color appearance of plasma was observed in order to judge the presence of gross hemolysis. Sonoclot and TEG were performed bedside at OSU. Following blood draws, catheters were flushed with $3 \mathrm{~mL}$ of heparinized saline. Subsequent blood samples were collected at the following time points utilizing a two-syringe technique to avoid heparin contamination of the samples; $0,30 \mathrm{~min}, 60 \mathrm{~min}, 4 \mathrm{~h}$, $8 \mathrm{~h}, 24 \mathrm{~h}, 48 \mathrm{~h}, 100 \mathrm{~h}$, and $120 \mathrm{~h} \mathrm{[54].} \mathrm{Briefly,} 3 \mathrm{~mL}$ of blood were drawn from the catheter and discarded prior to drawing the sample. The sample was drawn and then the catheter was again flushed with $2 \mathrm{~mL}$ of heparinized saline.

Sonoclot: Dynamic coagulation testing was utilized to demonstrate a more complete picture of the coagulopathy caused by M. fulvius envenoming. Sonoclot ${ }^{\circledR}$ utilizes viscoelastic coagulometry to asses the time until clot formation, the strength of the clot that is formed, clot retraction, and clot lysis [55]. Values provided by Sonoclot ${ }^{\circledR}$ testing are platelet function, activated clotting time (ACT $=$ time to 
initiate fibrin formation), clot rate (rate at which fibrinogen is converted to fibrin), and time to peak (time to reach peak clot strength).

Thromboelastography (TEG): TEG 5000 Thromboelastograph Hemostasis System (Haemoscope Corporation, Niles, IL, USA) was used to collect TEG measurements. Citrated blood (1 mL) was transferred to a kaolin tube (Kaolin activator, Haemonetics Corporation, Braintree, MI, USA). A sample of kaolin-activated blood was transferred to a cup with calcium chloride. The TEG was initiated at $37^{\circ} \mathrm{C}$. Paired samples were taken from corresponding citrated blood and kaolin-activated tubes and then placed into two separate disposable cups. Several TEG parameters were collected, including R-time (or clotting time; normal values: $2-8 \mathrm{~min}$ ), alpha angle (normal values: $55-788$ ), maximal amplitude (normal values: 51-69 mm), and LY30 (normal <8\%) [54]. An example of the technique compared to Sonoclot is shown as Figure 3B.

Author Contributions: M.R.L. Original concept, experimental design, and manuscript. L.L.G. Experimental design and conduct of experiments, veterinary care, data analysis, and manuscript. J.G. conduct of experiments, veterinary care, data analysis. S.P.S., T.C.B., P.E.B. data analyses, manuscript. J.M.G.: Experimental design, venom/antivenom dosing protocols, data analysis, and manuscript.

Funding: This research was funded by the United States government contract number W81XWH-17-C-0069.

Acknowledgments: We especially thank members of the Oklahoma State University Veterinary School for helping carry out these experiments in the most careful and caring manner, including but not limited to: Ellen Jackson, Aranxta Lasa, Kara Moore, Amy Lovett, Murphee Stepanik.

Conflicts of Interest: Ophirex, Inc. is a Public Benefit Corporation. M.R.L. is employed by Ophirex, Inc. and has stock; S.P.S., T.C.B., and P.E.B. have consulted for Ophirex, Inc. for compensation. L.L.G., J.G., J.M.G. have no competing interests.

\section{References}

1. Editorial Board. Snake-bite envenoming: A priority neglected tropical disease. Lancet (London, England) 2017, 390, 2. [CrossRef]

2. Sharma, S.K.; Chappuis, F.F.; Jha, N.; Bovier, P.A.; Loutan, L.; Koirala, S. Impact of snake bites and determinants of fatal outcomes in Southeastern Nepal. Am. J. Trop. Med. Hyg. 2004, 71, 234-238. [CrossRef] [PubMed]

3. Longbottom, J.; Shearer, F.M.; Devine, M.; Alcoba, G.; Chappuis, F.; Weiss, D.J.; Ray, S.E.; Ray, N.; Warrell, D.A.; Ruiz de Castañeda, R.; et al. Vulnerability to snakebite envenoming: A global mapping of hotspots. Lancet (London, England) 2018, 392, 673-684. [CrossRef]

4. Vaiyapuri, S.; Vaiyapuri, R.; Ashokan, R.; Ramasamy, K.; Nattamaisundar, K.; Jeyaraj, A.; Chandran, V.; Gajjeraman, P. Snakebite and Its Socio-Economic Impact on the Rural Population of Tamil Nadu, India. PLoS ONE 2013, 8, e80090. [CrossRef] [PubMed]

5. Harrison, R.A.; Hargreaves, A.; Wagstaff, S.C.; Faragher, B.; Lalloo, D.G. Snake Envenoming: A Disease of Poverty. PLoS Negl. Trop. Dis. 2009, 3, e569. [CrossRef] [PubMed]

6. Gutiérrez, J.M.; Calvete, J.J.; Habib, A.G.; Harrison, R.A.; Williams, D.J.; Warrell, D.A. Snakebite envenoming. Nat. Rev. Dis. Prim. 2017, 3, 17063. [CrossRef]

7. Lewin, M.; Samuel, S.; Merkel, J.; Bickler, P. Varespladib (LY315920) Appears to Be a Potent, Broad-Spectrum, Inhibitor of Snake Venom Phospholipase A2 and a Possible Pre-Referral Treatment for Envenomation. Toxins (Basel) 2016, 8, 248. [CrossRef] [PubMed]

8. Laustsen, A.H.; Engmark, M.; Milbo, C.; Johannesen, J.; Lomonte, B.; Gutierrez, J.M.; Lohse, B. From Fangs to Pharmacology: The Future of Snakebite Envenoming Therapy. Curr. Pharm. Des. 2016, 22, 5270-5293. [CrossRef] [PubMed]

9. Tasoulis, T.; Isbister, G.K. A Review and Database of Snake Venom Proteomes. Toxins (Basel) 2017, 9, 290. [CrossRef]

10. Calvete, J.J. Proteomic tools against the neglected pathology of snake bite envenoming. Expert Rev. Proteomics 2011, 8, 739-758. [CrossRef] [PubMed]

11. Harris, J.B.; Grubb, B.D.; Maltin, C.A.; Dixon, R. The neurotoxicity of the venom phospholipases A(2), notexin and taipoxin. Exp. Neurol. 2000, 161, 517-526. [CrossRef] [PubMed] 
12. Gutiérrez, J.M.; Ownby, C.L. Skeletal muscle degeneration induced by venom phospholipases A2: Insights into the mechanisms of local and systemic myotoxicity. Toxicon 2003, 42, 915-931. [CrossRef]

13. Clemetson, K.J.; Lu, Q.; Clemetson, J.M. Snake venom proteins affecting platelets and their applications to anti-thrombotic research. Curr. Pharm. Des. 2007, 13, 2887-2892. [CrossRef] [PubMed]

14. Stief, T.W. Phospholipase A(2) activates hemostasis. Drug Target Insights 2007, 2, 83-96. [CrossRef] [PubMed]

15. David, S.; Greenhalgh, A.D.; López-Vales, R. Role of phospholipase A2s and lipid mediators in secondary damage after spinal cord injury. Cell Tissue Res. 2012, 349, 249-267. [CrossRef] [PubMed]

16. Titsworth, W.L.; Liu, N.-K.; Xu, X.-M. Role of secretory phospholipase a(2) in CNS inflammation: Implications in traumatic spinal cord injury. CNS Neurol. Disord. Drug Targets 2008, 7, 254-269. [CrossRef] [PubMed]

17. Uhl, W.; Büchler, M.; Nevalainen, T.J.; Deller, A.; Beger, H.G. Serum phospholipase A2 in patients with multiple injuries. J. Trauma 1990, 30, 1285-1290. [CrossRef] [PubMed]

18. Liu, N.-K.; Titsworth, W.L.; Zhang, Y.P.; Xhafa, A.I.; Shields, C.B.; Xu, X.-M. Characterizing phospholipase A2-induced spinal cord injury-a comparison with contusive spinal cord injury in adult rats. Transl. Stroke Res. 2011, 2, 608-618. [CrossRef] [PubMed]

19. Gutiérrez, J.M.; Lomonte, B.; Sanz, L.; Calvete, J.J.; Pla, D. Immunological profile of antivenoms: Preclinical analysis of the efficacy of a polyspecific antivenom through antivenomics and neutralization assays. J. Proteomics 2014, 105, 340-350. [CrossRef]

20. Sanhajariya, S.; Duffull, S.B.; Isbister, G.K. Pharmacokinetics of Snake Venom. Toxins (Basel) 2018, 10, 73. [CrossRef] [PubMed]

21. Laustsen, A.H.; Gutiérrez, J.M.; Knudsen, C.; Johansen, K.H.; Bermúdez-Méndez, E.; Cerni, F.A.; Jürgensen, J.A.; Ledsgaard, L.; Martos-Esteban, A.; Øhlenschlæger, M.; et al. Pros and cons of different therapeutic antibody formats for recombinant antivenom development. Toxicon 2018, 146, 151-175. [CrossRef] [PubMed]

22. Adis R\&D Profile Varespladib. Am. J. Cardiovasc. Drugs 2011, 11, 137-143.

23. Wang, Y.; Zhang, J.; Zhang, D.; Xiao, H.; Xiong, S.; Huang, C. Exploration of the Inhibitory Potential of Varespladib for Snakebite Envenomation. Molecules 2018, 23, 391. [CrossRef] [PubMed]

24. Xiao, H.; Li, H.; Zhang, D.; Li, Y.; Sun, S.; Huang, C.; Xiao, H.; Li, H.; Zhang, D.; Li, Y.; Sun, S.; Huang, C. Inactivation of Venom PLA2 Alleviates Myonecrosis and Facilitates Muscle Regeneration in Envenomed Mice: A Time Course Observation. Molecules 2018, 23, 1911. [CrossRef]

25. Dennis, E.A.; Cao, J.; Hsu, Y.-H.; Magrioti, V.; Kokotos, G. Phospholipase A2 Enzymes: Physical Structure, Biological Function, Disease Implication, Chemical Inhibition, and Therapeutic Intervention. Chem. Rev. 2011, 111, 6130-6185. [CrossRef] [PubMed]

26. Lewin, M.R.; Gutiérrez, J.M.; Samuel, S.P.; Herrera, M.; Bryan-Quirós, W.; Lomonte, B.; Bickler, P.E.; Bulfone, T.C.; Williams, D.J. Delayed Oral LY333013 Rescues Mice from Highly Neurotoxic, Lethal Doses of Papuan Taipan (Oxyuranus scutellatus) Venom. Toxins (Basel) 2018, 10, 380. [CrossRef] [PubMed]

27. Vergara, I.; Pedraza-Escalona, M.; Paniagua, D.; Restano-Cassulini, R.; Zamudio, F.; Batista, C.V.F.; Possani, L.D.; Alagón, A. Eastern coral snake Micrurus fulvius venom toxicity in mice is mainly determined by neurotoxic phospholipases A2. J. Proteomics 2014, 105, 295-306. [CrossRef] [PubMed]

28. Arce-Bejarano, R.; Lomonte, B.; Gutiérrez, J.M. Intravascular hemolysis induced by the venom of the Eastern coral snake, Micrurus fulvius, in a mouse model: Identification of directly hemolytic phospholipases A2. Toxicon 2014, 90, 26-35. [CrossRef] [PubMed]

29. De Roodt, A.R.; Lago, N.R.; Stock, R.P. Myotoxicity and nephrotoxicity by Micrurus venoms in experimental envenomation. Toxicon 2012, 59, 356-364. [CrossRef] [PubMed]

30. Smyrnioudis, M.E.; O’Rourke, D.P.; Rosenbaum, M.D.; Brewer, K.L.; Meggs, W.J. Long-term efficacy of pressure immobilization bandages in a porcine model of coral snake envenomation. Am. J. Emerg. Med. 2014, 32, 1024-1026. [CrossRef] [PubMed]

31. German, B.T.; Hack, J.B.; Brewer, K.; Meggs, W.J. Pressure-Immobilization Bandages Delay Toxicity in a Porcine Model of Eastern Coral Snake (Micrurus fulvius fulvius) Envenomation. Ann. Emerg. Med. 2005, 45, 603-608. [CrossRef] [PubMed]

32. Parker-Cote, J.L.; O’Rourke, D.P.; Brewer, K.L.; Lertpiriyapong, K.; Punja, M.; Bush, S.P.; Miller, S.N.; Meggs, W.J. Efficacy of Trypsin in Treating Coral Snake Envenomation in the Porcine Model. J. Med. Toxicol. 2015, 11, 430-432. [CrossRef] [PubMed] 
33. Hack, J.B.; Deguzman, J.M.; Brewer, K.L.; Meggs, W.J.; O’Rourke, D.; O'rourke, D. A Localizing Circumferential Compression Device Increases Survival after Coral Snake Envenomation to the Torso of an Animal Model. JEM 2011, 41, 102-107. [CrossRef] [PubMed]

34. LD50 and Venom Yields ISnakedatabase.org. Available online: http://snakedatabase.org/pages/ld50.php (accessed on 28 August 2018).

35. Silva, A.; Johnston, C.; Kuruppu, S.; Kneisz, D.; Maduwage, K.; Kleifeld, O.; Smith, A.I.; Siribaddana, S.; Buckley, N.A.; Hodgson, W.C.; et al. Clinical and Pharmacological Investigation of Myotoxicity in Sri Lankan Russell's Viper (Daboia russelii) Envenoming. PLoS Negl. Trop. Dis. 2016, 10, e0005172. [CrossRef] [PubMed]

36. Silva, A.; Hodgson, W.; Isbister, G. Cross-Neutralisation of In Vitro Neurotoxicity of Asian and Australian Snake Neurotoxins and Venoms by Different Antivenoms. Toxins (Basel) 2016, 8, 302. [CrossRef] [PubMed]

37. Fernández, M.L.; Quartino, P.Y.; Arce-Bejarano, R.; Fernández, J.; Camacho, L.F.; Gutiérrez, J.M.; Kuemmel, D.; Fidelio, G.; Lomonte, B. Intravascular hemolysis induced by phospholipases A 2 from the venom of the Eastern coral snake, Micrurus fulvius: Functional profiles of hemolytic and non-hemolytic isoforms. Toxicol. Lett. 2018, 286, 39-47. [CrossRef]

38. Davis, S.S.; Illum, L.; Hinchcliffe, M. Gastrointestinal transit of dosage forms in the pig. J. Pharm. Pharmacol. 2001, 53, 33-39. [CrossRef] [PubMed]

39. World Health Organization. WHO Guidelines for the Production, Control and Regulation of Snake Antivenom Immunoglobulins; WHO: Geneva, Switzerland, 2010.

40. Lomonte, B.; Rey-Suárez, P.; Fernández, J.; Sasa, M.; Pla, D.; Vargas, N.; Bénard-Valle, M.; Sanz, L.; Corrêa-Netto, C.; Núñez, V.; et al. Venoms of Micrurus coral snakes: Evolutionary trends in compositional patterns emerging from proteomic analyses. Toxicon 2016, 122, 7-25. [CrossRef] [PubMed]

41. Kini, R.M. Structure-function relationships and mechanism of anticoagulant phospholipase A2 enzymes from snake venoms. Toxicon 2005, 45, 1147-1161. [CrossRef] [PubMed]

42. Morgan, D. Snakes in Myth, Magic, and History: The Story of a Human Obsession; Praeger: Santa Barbara, CA, USA, 2008; ISBN 0313352925.

43. Arias, A.S.; Rucavado, A.; Gutierrez, J.-M. Peptidomimetic hydroxamate metalloproteinase inhibitors abrogate local and systemic toxicity induced by Echis ocellatus (saw-scaled) snake venom. Toxicon 2017, 132, 40-49. [CrossRef] [PubMed]

44. Escalante, T.; Franceschi, A.; Rucavado, A.; Gutiérrez, J.M. Effectiveness of batimastat, a synthetic inhibitor of matrix metalloproteinases, in neutralizing local tissue damage induced by $\mathrm{BaP} 1$, a hemorrhagic metalloproteinase from the venom of the snake bothrops asper. Biochem. Pharmacol. 2000, 60, 269-274. [CrossRef]

45. Herzel, B.; Samuel, S.P.; Bulfone, T.C.; Raj, C.S.; Lewin, M.R.; Kahn, J.G. Snakebite: An Exploratory Cost-Effectiveness Analysis of Adjunct Treatment Strategies. Am. J. Trop. Med. Hyg. 2018, in press. [CrossRef] [PubMed]

46. Hessel, M.M.; McAninch, S.A. Coral Snake Toxicity; StatPearls: Tampa, FL, USA, 2018.

47. Sheikh, S.; Leffers, P. Emergency department management of North American snake envenomations. Emerg. Med. Pract. 2018, 20, 1-26. [PubMed]

48. Sasaki, J.; Khalil, P.A.; Chegondi, M.; Raszynski, A.; Meyer, K.G.; Totapally, B.R. Coral Snake Bites and Envenomation in Children. Pediatr. Emerg. Care 2014, 30, 262-265. [CrossRef] [PubMed]

49. Kitchens, C.S.; Van Mierop, L.H. Envenomation by the Eastern coral snake (Micrurus fulvius fulvius). A study of 39 victims. JAMA 1987, 258, 1615-1618. [CrossRef] [PubMed]

50. Abraham, E.; Naum, C.; Bandi, V.; Gervich, D.; Lowry, S.F.; Wunderink, R.; Schein, R.M.; Macias, W.; Skerjanec, S.; Dmitrienko, A.; et al. Efficacy and safety of LY315920Na/S-5920, a selective inhibitor of 14-kDa group IIA secretory phospholipase A2, in patients with suspected sepsis and organ failure. Crit. Care Med. 2003, 31, 718-728. [CrossRef] [PubMed]

51. Rojas, G.; Jiménez, J.M.; Gutiérrez, J.M. Caprylic acid fractionation of hyperimmune horse plasma: Description of a simple procedure for antivenom production. Toxicon 1994, 32, 351-363. [CrossRef]

52. Arce, V.; Rojas, E.; Ownby, C.L.; Rojas, G.; Gutiérrez, J.M. Preclinical assessment of the ability of polyvalent (Crotalinae) and anticoral (Elapidae) antivenoms produced in Costa Rica to neutralize the venoms of North American snakes. Toxicon 2003, 41, 851-860. [CrossRef]

53. Flournoy, W.S.; Mani, S. Percutaneous external jugular vein catheterization in piglets using a triangulation technique. Lab. Anim. 2009, 43, 344-349. [CrossRef] [PubMed] 
54. Larréché, S.; Jean, F.-X.; Benois, A.; Mayet, A.; Bousquet, A.; Vedy, S.; Clapson, P.; Dehan, C.; Rapp, C.; Kaiser, E.; et al. Thromboelastographic study of the snakebite-related coagulopathy in Djibouti. Blood Coagul. Fibrinol. 2018, 29, 196-204. [CrossRef]

55. Hett, D.A.; Walker, D.; Pilkington, S.N.; Smith, D.C. Sonoclot analysis. Br. J. Anaesth. 1995, 75, 771-776. [CrossRef] [PubMed] 